\title{
Improvement research on the initial solution prediction of the one-step algorithm for bus rollover collision
}

Tong Wang ( $\nabla$ wangtong@chd.edu.cn )

\section{Original Article}

Keywords: Bus rollover, One-step collision algorithm, Total strain theory, Initial solution prediction, Principle of nodal coordinates interpolation

Posted Date: March 25th, 2020

DOl: https://doi.org/10.21203/rs.3.rs-18541/v1

License: (c) (1) This work is licensed under a Creative Commons Attribution 4.0 International License. Read Full License 


\title{
Improvement research on the initial solution prediction of the one-step algorithm for bus rollover collision
}

\author{
Tong Wang \\ (Department of Vehicle Engineering, School of Automotive, Chang'an University, Xi'an, 710064, \\ China)
}

\begin{abstract}
To solve the problem that the computational efficiency of the initial solution prediction based on the maximum inertial loading in the original one-step algorithm for bus rollover collision is a bit low, a new initial solution prediction method based on the principle of nodal coordinates interpolation of the standard template of structural deformation is proposed to improve the original one-step algorithm for bus rollover collision. A typical 12-meter bus body section is selected as the research object, and the simulation result of the improved algorithm is compared with the original algorithm. The compare result shows that the computational precision of the improved algorithm is basically kept, and the computational efficiency is greatly improved. The effectiveness of practical engineering application of the proposed initial solution prediction method is verified.
\end{abstract}

Keywords: Bus rollover; One-step collision algorithm; Total strain theory; Initial solution prediction; Principle of nodal coordinates interpolation

\section{Introduction}

With the rapid expansion of the public traffic, the bus has become one of the most popular public transport tools [1]. Meanwhile, the increasing number of traffic accidents related to the bus has caused great loss of human lives and properties [2]. Among all kinds of traffic accidents related to the bus, rollover collision is of the most severity since it may cause mass deaths and injuries in only one accident [3]. How to prevent the happening of rollover accidents in the maximum degree, strengthen the research on the rollover collision safety of the bus structure to improve the performance of bus rollover safety, and reduce the injury of driver and passengers have become one of the most important society issue that are common concern for the whole society and needed to try hard to be solved $[4,5]$.

According to the core idea of the one-step fast simulation algorithm for sheet metal forming, a new algorithm, one-step algorithm for bus rollover collision, is proposed for the simulation of bus rollover collision [6]. For the one-step fast simulation algorithm for sheet metal forming, Guo began to propose the "Inverse method" in 1989, and the thickness of the stamping parts and the stress distribution were predicted [7-12]. Shen discussed the application of using the one-step inverse method based on the deformation theory into the simulation process of sheet metal forming, and the effectiveness of the method is verified by comparing the result with the incremental method [13-15]. $\mathrm{Hu}$ and Liu carried out the research on the wrinkle, rebound, and instability problem of the simulation process of sheet metal forming by using the one-step inverse element method [16-18]. Soon afterwards, $\mathrm{Na}$ and Chen preliminarily discussed the "one-step positive" algorithm for sheet metal forming based on the one-step inverse algorithm for sheet metal forming which is more applicable for the engineering in the future, and the performances of the sheet metal forming could be quickly evaluated with good application effect [19-22]. The one-step algorithm for bus rollover

\footnotetext{
* Corresponding author. E-mail: wangtong@chd.edu.cn
} 
collision is also based on total strain theory by referring to the core idea of the algorithm for sheet metal forming, and the energy transforming relationship of the process of rollover collision is adopted at the same time. The computational efficiency gains a lot with a slightly sacrifice of the computational precision comparing with the incremental method software such as LS-DYNA. The rollover safety performance of the bus structure can be quickly evaluated at the initial stage of bus body design, and the development cycle for bus products can be reduced sharply.

Due to the use of total strain theory, the initial solution satisfying the conditions of energy translation and deformation needs to be obtained at the maximum deformation station for Newton-Raphson iteration. Adopt the "Initial solution prediction method based on the maximum inertial loading" proposed by the author for the first time, and the initial solution satisfying the deformation conditions can be obtained by computing the elastic finite element approximation equilibrium equation of the structure and combining the energy translation relationship during the rollover collision process [6]. For the computational efficiency, it is brought down for the requirement of computing the finite element equilibrium equation of the structure. For the computational precision, there is no influence on the simulation result for the precision of the initial solution in theory. But the closer to the truly final deformation, the higher of the computational efficiency of the algorithm. To improve the computational efficiency one step further, a new initial solution prediction method based on the principle of nodal coordinates interpolation of the standard template of structure deformation is proposed to improve the process of initial solution prediction of the original one-step algorithm [6]. Predict that the computational precision can be basically kept, and the computational efficiency can be further improved with greatly reducing the computational workload. At the initial stage of bus body design, the rollover safety performance of the bus structure can be evaluated and improved more quickly, and the development cycle for bus products can be reduced sharply one step further.

\section{The initial solution prediction method based on the principle of nodal coordinates interpolation of the standard template}

For the construction of the standard template and the prediction method of the initial solution, it is illustrated by taking a 12-meter bus as the example in this paper. This method can be used for other length and type buses as well. For the reason that the closed-loops of road bus body structure perform the decisive role to improve the rollover collision safety of the whole bus [23]. So the standard template of the initial solution is constructed based on the closed-loops of a 12-meter road bus body. For the proposed initial solution prediction method, the standard template of bus body structure deformation after and before is constructed by analyzing the deformation results of rollover collision structure of several 12-meter road buses. The initial solution needed by the one-step algorithm for bus rollover collision is quickly obtained by exploring the related mapping relationship of each node of the structure deformation after and before in the standard template and by using the interpolation method of nodal generalized coordinates.

According to the simplification of the simulation process of rollover collision in the original algorithm, the coordinate of each node of the structure in the $\mathrm{X}$ direction can be seen as approximately remaining unchanged during the collision process of fixed-axis rotation dropping for the bus structure. The basic idea by using the standard template method for the initial solution prediction is: Firstly, referring to the regulation of the structure deformation, a group of standard templates used for the prediction of the maximum deformation of rollover collision for nearly all of the 12-meter road buses in the YZ plane are constructed by using some finite element analysis data of the original structures before the rollover collision and the maximum deformation structures after the rollover collision of several typical closed-loops of the 12-meter road buses. Secondly, for any 
one 12-meter road bus body structure, the final deformations are unknown, the new generalized coordinates of each node in the standard template of the maximum deformation configuration are ensured by using the nodal interpolation principle of the generalized coordinates according to the position of each node of the original configuration in the standard template of the original configuration. Thirdly, the maximum deformation configuration of the one-step algorithm for bus rollover collision is obtained combining the coordinates of $\mathrm{X}$ direction of each node of the original configuration. Then by carrying out the process of the energy equilibrium iteration and the process of the contact judgement and modification, the initial solution of the algorithm is quickly obtained, which satisfies the energy translation relationship of rollover collision and does not penetrate into the floor meanwhile. Finally, Newton-Raphson iteration can be carried out for the generalized imbalanced forces of each node of the obtained structure above, and the final structure deformation is obtained.

\subsection{The construction of the standard template of original configuration}

To obtain the general discipline of motion and deformation and to construct the standard template of the maximum deformation configuration of the structure, the standard template of the original configuration before the deformation of the structure needs to be constructed at first. In order to make the constructed standard template own the general reference value, three typical closed-loops from three different 12-meter road bus body skeletons are selected as the reference structures of the construction of the original configuration in this paper. The finite element models are shown in Figure 1. There is nearly no difference for the outline size of the structures of the three closed-loops, but there are some differences for the section sizes of the thin-wall bars of the structures and the structural shapes of the underbeds.

Figure 1. The finite element model of three closed-loop structures

Referring to the finite element models of the three closed-loop structures, each of the maximum values is selected according to the height and width of the three section planes. The related section sizes are enlarged properly, and the height and width sizes of the standard template of the original configuration are finally ensured as $3325 \mathrm{~mm}^{*} 2520 \mathrm{~mm}$. The three closed-loops are separately displaced in the standard template ensured above in the YZ plane, shown as Figure 2. For the standard templates that the three closed-loops are in, each of them is separately divided into the grille of 19 lines and 14 columns by using the rectangle grid, of which the height and width sizes are $175 \mathrm{~mm} * 180 \mathrm{~mm}$. For the reason that the three closed-loops are all from 12-meter road bus structures, all of the three closed-loop structures can well adjust the constructed standard template. The templates in Figure 2 can basically reflect the relative position relationship between each node of the original structure and the template for all 12-meter road buses before the rollover collision.

Figure 2. The standard template of the original configuration of three closed-loop structures

Compare, adjust and integrate the number, array styles and positions of the grids for each template in Figure 2, a standard template of the original configuration is obtained, which is nearly suitable for all 12-meter road buses, shown as Figure 3. All of the generalized coordinates of the template can be obtained by computing. The boundary sizes and the grid sizes of the standard template can be further optimized and improved by referring to more kinds of 12-meter buses to 
reinforce the scope of the application, computational precision and efficiency for the 12-meter buses in the future. The construction method of the standard template of the original configuration for the rollover collision of the 12-meter road buses is suitable for the bus products of other lengths and types in the same way.

Figure 3. The standard template of the original configuration

\subsection{The construction of the standard template of maximum deformation configuration}

To predict the maximum deformation configuration of the structure after the bus rollover collision, the standard template of maximum deformation configuration needs to be constructed based on the standard template of the original configuration shown in Figure 3, which has the widespread references for all 12-meter road buses. Conduct the analysis of rollover collision for the three 12-meter road buses mentioned above by using the LS-DYNA software. Extract the deformation results of the three closed-loop structures shown in Figure 1. Start from the final deformations of the closed-loop structures to seek the general regulation of the structure deformations after bus rollover collision. The final deformations of rollover collision of the three closed-loop structures are shown as Figure 4.

Figure 4. The final deformation of rollover collision of the three closed-loop structures

Put the final deformation configurations of the three closed-loops in the standard template of the original configuration in Figure 3. Adjust the positions and shapes of the grids of the template properly referring to the deformation trends of the structures of the three 12-meter buses. Ensure that the trends of the movements and deformations of the grids of the standard template are in harmony with the deformations of the bus body structures. Keep the number and the arrangement of the nodes of the structure in each grid of the template the same with the standard template of the original configuration. And the standard templates of the maximum deformation configuration of the three closed-loops are constructed separately. These templates can basically reflect the deformation forms of the structures of all 12-meter road buses after the rollover collision, shown as Figure 5.

Figure 5. The standard template of maximum deformation configuration of the three closed-loops

According to the three standard templates of the maximum deformation configuration of the three closed-loop structures in Figure 5, compare, adjust and integrate the number, array style and the position of the grids for each template, and a standard template of maximum deformation configuration is obtained, which is nearly suitable for all 12-meter road buses, shown as Figure 6. All of the generalized coordinates (position and rotation) of each node of the standard template can be obtained by computing. And then, the maximum deformation configuration of every closed-loop, bus body section, even the structure of whole bus can be predicted by using the proposed standard template. The boundary size and the grid size of the standard template can be further optimized and improved by referring to more different kinds of 12-meter buses to improve the scope of application, computational precision and efficiency for the 12-meter buses in the future. The construction method of the standard template of maximum deformation configuration for the rollover collision of 
the 12-meter road buses is suitable for the bus products of other lengths and types in the same way.

Figure 6. The standard template of maximum deformation configuration

So, using the group of standard templates of Figure 3 and Figure 6, the new generalized coordinates of each node of the structure in the standard template of the maximum deformation configuration can be ensured according to the position of each node of the original structure in the standard template of the original configuration by using the interpolation method of the nodal generalized coordinates. Then the maximum deformation configuration of the structure is obtained, and the initial solution of the one-step algorithm for bus rollover collision can be computed. For the standard template groups of road buses of other lengths and types used for the prediction of the maximum deformation configuration of rollover collision, the construction method can be conducted by the method described above.

\subsection{The prediction of the initial solution based on the interpolation principle of the generalized nodal coordinates}

To make the initial solution prediction by using the standard templates constructed above, the nodal interpolation principle of the generalized coordinates is used for computing the generalized coordinates of each node of the maximum deformation configuration.

Firstly, compute the interpolation coefficients according to the position of each node in the standard template of the original configuration before the deformation of the structure. The detailed computation process is shown as below:

For the reason that the coordinates of each node of the structure in the X direction can be seen as approximately remaining unchanged during the collision dropping process of fixed-axis rotation of the bus structure, the position coordinates of the $\mathrm{Y}$ and $\mathrm{Z}$ directions need to be computed only. In the constructed group of standard templates of Figure 3 and Figure 6, the corresponding relations for the same node A (a) of the original structure and the maximum deformation structure, shown as Figure 7.

Figure 7. The nodal corresponding relations of the group of standard templates

In the $\mathrm{YZ}$ plane, assume that the coordinate of a node $\mathrm{A}$ is $\left(\mathrm{Y}_{\mathrm{A}}, \mathrm{Z}_{\mathrm{A}}\right)$ in the original configuration. As is shown in Figure 3, the coordinates of the four nodes of the corresponding grid $\mathrm{M}$ of the standard template that the node $\mathrm{A}$ is in $\operatorname{are~} \mathrm{I}\left(\mathrm{Y}_{\mathrm{IA}}, \mathrm{Z}_{\mathrm{IA}}\right), \mathrm{J}\left(\mathrm{Y}_{\mathrm{JA}}, \mathrm{Z}_{\mathrm{JA}}\right), \mathrm{K}\left(\mathrm{Y}_{\mathrm{KA}}, \mathrm{Z}_{\mathrm{KA}}\right), \mathrm{L}\left(\mathrm{Y}_{\mathrm{LA}}, \mathrm{Z}_{\mathrm{LA}}\right)$, of which the values are known. And the coordinate of node A can be obtained by the interpolation of the coordinates of the four nodes of the grid $\mathrm{M}$, and the interpolation coefficients $r_{\mathrm{A}}, s_{\mathrm{A}}$ can be calculated by use of Equation (1):

$$
\left\{\begin{array}{l}
Y_{\mathrm{A}}=N_{1 \mathrm{~A}} Y_{\mathrm{IA}}+N_{2 \mathrm{~A}} Y_{\mathrm{JA}}+N_{3 \mathrm{~A}} Y_{\mathrm{KA}}+N_{4 \mathrm{~A}} Y_{\mathrm{LA}} \\
Z_{\mathrm{A}}=N_{1 \mathrm{~A}} Z_{\mathrm{IA}}+N_{2 \mathrm{~A}} Z_{\mathrm{JA}}+N_{3 \mathrm{~A}} Z_{\mathrm{KA}}+N_{4 \mathrm{~A}} Z_{\mathrm{LA}}
\end{array}\right.
$$


where

$$
\mathrm{N}_{1 \mathrm{~A}}=\frac{1}{4}\left(1-r_{\mathrm{A}}\right)\left(1-s_{\mathrm{A}}\right), \mathrm{N}_{2 \mathrm{~A}}=\frac{1}{4}\left(1+r_{\mathrm{A}}\right)\left(1-s_{\mathrm{A}}\right)
$$

$$
\mathrm{N}_{3 \mathrm{~A}}=\frac{1}{4}\left(1+r_{\mathrm{A}}\right)\left(1+s_{\mathrm{A}}\right), \mathrm{N}_{4 \mathrm{~A}}=\frac{1}{4}\left(1-r_{\mathrm{A}}\right)\left(1+s_{\mathrm{A}}\right)
$$

are the shape functions of the square element, of which the centroid is $(0,0)$ and the side length is 2 .

Then Equation (2) can be obtained as following:

$$
\left\{\begin{array}{l}
r_{\mathrm{A}}=-\frac{4 \mathrm{Z}_{\mathrm{A}}-\mathrm{Z}_{\mathrm{IA}}-\mathrm{Z}_{\mathrm{JA}}-\mathrm{Z}_{\mathrm{KA}}-\mathrm{Z}_{\mathrm{LA}}}{\mathrm{Z}_{\mathrm{IA}}-\mathrm{Z}_{\mathrm{JA}}+\mathrm{Z}_{\mathrm{KA}}-\mathrm{Z}_{\mathrm{LA}}} \\
s_{\mathrm{A}}=\frac{4 \mathrm{Y}_{\mathrm{A}}-\mathrm{Y}_{\mathrm{IA}}-\mathrm{Y}_{\mathrm{JA}}-\mathrm{Y}_{\mathrm{KA}}-\mathrm{Y}_{\mathrm{LA}}}{\mathrm{Y}_{\mathrm{KA}}+\mathrm{Y}_{\mathrm{LA}}-\mathrm{Y}_{\mathrm{IA}}-\mathrm{Y}_{\mathrm{JA}}}
\end{array}\right.
$$

The position of each node of the structure in the standard template of the original configuration of Figure 3 can be only determined by use of the interpolation coefficient $r_{\mathrm{A}}, s_{\mathrm{A}}$ computed by Equation (2).

Secondly, compute the position coordinates of node a, and the detailed process is as following:

The deformation of the structure occurs after the rollover collision, but the position coordinates of the nodes of the maximum deformation configuration are unknown. Hence, the standard template of the maximum deformation configuration is brought in shown as Figure 6. In Figure 7, the node A moves to the position of node a along with the grid M. The coordinate is changed to $\left(y_{\mathrm{a}}, z_{\mathrm{a}}\right)$, and the value is unknown. The coordinates of the four nodes of the grid $M$ are changed to $i\left(y_{i \mathrm{a}}, z_{i \mathrm{a}}\right), j\left(y_{j \mathrm{a}}, z_{j \mathrm{a}}\right), k\left(y_{k \mathrm{a}}, z_{k \mathrm{a}}\right), l\left(y_{l \mathrm{a}}, z_{l \mathrm{a}}\right)$ for the changes of the shape and position, but the value is known. Before and after the deformation of the structure, the relative position remains unchanged for node $\mathrm{A}(\mathrm{a})$ in the grid $\mathrm{M}$, and the position coordinate of node a after the deformation of the structure can be ensured through the interpolation coefficients $r_{\mathrm{A}}, s_{\mathrm{A}}$.

The position coordinates of the new node a $\left(x_{\mathrm{a}}, y_{\mathrm{a}}, z_{\mathrm{a}}\right)$ in the standard template of the maximum deformation configuration shown in Figure 6 after the deformation of the structure can be ensured by replacing the position coordinates of the four nodes of the grid $\mathrm{M}$ of the original structure as $i\left(y_{i \mathrm{a}}, z_{i \mathrm{a}}\right), j\left(y_{j \mathrm{a}}, z_{j \mathrm{a}}\right), k\left(y_{k \mathrm{a}}, z_{k \mathrm{a}}\right), l\left(y_{l \mathrm{a}}, z_{l \mathrm{a}}\right)$ in Equation (1) combing Equation (2) and the coordinate of the $\mathrm{X}$ direction of node $\mathrm{A}$.

Thirdly, compute the rotation corner coordinates of the each node after the deformation of the structure, and the detailed process is as following:

For there is no deformation for the original structure, the rotation corners of each node are zero, and the rotation corner coordinates of each node of the grids of the standard template of the original configuration are zero too. To compute the rotation corners of each node around the three coordinate axles of the maximum deformation configuration, the values can be obtained by the interpolation for the rotation corner coordinates of each grid node in the standard template of the maximum deformation configuration in Figure 6 in this paper. The nodal rotation corner values of each grid of the standard template can be obtained by inversely interpolating for the values of three rotation corners of each node of several known maximum deformation configurations shown as Figure 5. 
The coordinates of the three rotation corners of each node of the grid of the standard template of the maximum deformation configuration can be obtained by averaging the computational results. To improve the precision of the rotation corner coordinates of each node of the grid of the proposed template and the universal applicability of the 12-meter road bus body structures, several inversely interpolating computational processes of the nodes in the mentioned grids need to be carried out by using several maximum deformation configurations that are known, and several average values of the nodal rotation corners need to be computed at the same time.

Take the grid M shown in Figure 7 as example still. To compute the rotation coordinates of the four nodes after the deformation of the structure, four nodes $B(b), C(c), D(d), E(e)$ of the deformation of the structure shown in the grid M in Figure 5 are selected at will, and the three rotation corners of the four nodes can be computed by use of Equation (3) to (6):

$$
\begin{array}{r}
\left\{\begin{array}{l}
\theta_{\mathrm{b} x}=\mathrm{N}_{1 \mathrm{~B}} \theta_{i x}+\mathrm{N}_{2 \mathrm{~B}} \theta_{j x}+\mathrm{N}_{3 \mathrm{~B}} \theta_{k x}+\mathrm{N}_{4 \mathrm{~B}} \theta_{l x} \\
\theta_{\mathrm{b} y}=\mathrm{N}_{1 \mathrm{~B}} \theta_{i y}+\mathrm{N}_{2 \mathrm{~B}} \theta_{j y}+\mathrm{N}_{3 \mathrm{~B}} \theta_{k y}+\mathrm{N}_{4 \mathrm{~B}} \theta_{l y} \\
\theta_{\mathrm{b} z}=\mathrm{N}_{1 \mathrm{~B}} \theta_{i z}+\mathrm{N}_{2 \mathrm{~B}} \theta_{j z}+\mathrm{N}_{3 \mathrm{~B}} \theta_{k z}+\mathrm{N}_{4 \mathrm{~B}} \theta_{l z}
\end{array}\right. \\
\left\{\begin{array}{l}
\theta_{\mathrm{c} x}=\mathrm{N}_{1 \mathrm{C}} \theta_{i x}+\mathrm{N}_{2 \mathrm{C}} \theta_{j x}+\mathrm{N}_{3 \mathrm{C}} \theta_{k x}+\mathrm{N}_{4 \mathrm{C}} \theta_{l x} \\
\theta_{\mathrm{c} y}=\mathrm{N}_{1 \mathrm{C}} \theta_{i y}+\mathrm{N}_{2 \mathrm{C}} \theta_{j y}+\mathrm{N}_{3 \mathrm{C}} \theta_{k y}+\mathrm{N}_{4 \mathrm{C}} \theta_{l y} \\
\theta_{\mathrm{c} z}=\mathrm{N}_{1 \mathrm{C}} \theta_{i z}+\mathrm{N}_{2 \mathrm{C}} \theta_{j z}+\mathrm{N}_{3 \mathrm{C}} \theta_{k z}+\mathrm{N}_{4 \mathrm{C}} \theta_{l z}
\end{array}\right. \\
\begin{cases}\theta_{\mathrm{d} x}=\mathrm{N}_{1 \mathrm{D}} \theta_{i x}+\mathrm{N}_{2 \mathrm{D}} \theta_{j x}+\mathrm{N}_{3 \mathrm{D}} \theta_{k x}+\mathrm{N}_{4 \mathrm{D}} \theta_{l x} \\
\theta_{\mathrm{d} y}=\mathrm{N}_{1 \mathrm{D}} \theta_{i y}+\mathrm{N}_{2 \mathrm{D}} \theta_{j y}+\mathrm{N}_{3 \mathrm{D}} \theta_{k y}+\mathrm{N}_{4 \mathrm{D}} \theta_{l y} \\
\theta_{\mathrm{d} z}=\mathrm{N}_{1 \mathrm{D}} \theta_{i z}+\mathrm{N}_{2 \mathrm{D}} \theta_{j z}+\mathrm{N}_{3 \mathrm{D}} \theta_{k z}+\mathrm{N}_{4 \mathrm{D}} \theta_{l z}\end{cases} \\
\begin{cases}\theta_{\mathrm{e} x}=\mathrm{N}_{1 \mathrm{E}} \theta_{i x}+\mathrm{N}_{2 \mathrm{E}} \theta_{j x}+\mathrm{N}_{3 \mathrm{E}} \theta_{k x}+\mathrm{N}_{4 \mathrm{E}} \theta_{l x} \\
\theta_{\mathrm{e} y}=\mathrm{N}_{1 \mathrm{E}} \theta_{i y}+\mathrm{N}_{2 \mathrm{E}} \theta_{j y}+\mathrm{N}_{3 \mathrm{E}} \theta_{k y}+\mathrm{N}_{4 \mathrm{E}} \theta_{l y} \\
\theta_{\mathrm{e} z}=\mathrm{N}_{1 \mathrm{E}} \theta_{i z}+\mathrm{N}_{2 \mathrm{E}} \theta_{j z}+\mathrm{N}_{3 \mathrm{E}} \theta_{k z}+\mathrm{N}_{4 \mathrm{E}} \theta_{l z}\end{cases}
\end{array}
$$

where

$$
\mathrm{N}_{1 \xi}=\frac{1}{4}\left(1-r_{\xi}\right)\left(1-s_{\xi}\right), \mathrm{N}_{2 \xi}=\frac{1}{4}\left(1+r_{\xi}\right)\left(1-s_{\xi}\right)
$$

$$
\mathrm{N}_{3 \xi}=\frac{1}{4}\left(1+r_{\xi}\right)\left(1+s_{\xi}\right), \mathrm{N}_{4 \xi}=\frac{1}{4}\left(1-r_{\xi}\right)\left(1+s_{\xi}\right)
$$

$(\xi$ selects $\mathrm{B}, \mathrm{C}, \mathrm{D}, \mathrm{E})$ are known, $r_{\xi}, s_{\xi}$ can be calculated by use of Equation

(2), and the values of $\left(\theta_{\mathrm{b} x}, \theta_{\mathrm{b} y}, \theta_{\mathrm{b} z}\right),\left(\theta_{\mathrm{c} x}, \theta_{\mathrm{c} y}, \theta_{\mathrm{c} z}\right),\left(\theta_{\mathrm{d} x}, \theta_{\mathrm{d} y}, \theta_{\mathrm{d} z}\right),\left(\theta_{\mathrm{ex}}, \theta_{\mathrm{e} y}, \theta_{\mathrm{e} z}\right)$ are all known.

For the rotation corner coordinates of the four nodes of the grid $M$ $i\left(\theta_{i x}, \theta_{i y}, \theta_{i z}\right), j\left(\theta_{j x}, \theta_{j y}, \theta_{j z}\right), k\left(\theta_{k x}, \theta_{k y}, \theta_{k z}\right), l\left(\theta_{l x}, \theta_{l y}, \theta_{l z}\right)$ are unknown, the rotation coordinates of each node of the grid can be computed by combining Equation (3) to (6).

For node $i\left(\theta_{i x}, \theta_{i y}, \theta_{i z}\right)$, it is the common node of the four grids $\mathrm{M}_{1} \mathrm{M}_{1}, \mathrm{M}_{2}, \mathrm{M}_{3}$ in the standard template of the maximum deformation configuration, shown as Figure 8. So the average value needs to be calculated by using the value of the rotation corner of node $i\left(\theta_{i x}, \theta_{i y}, \theta_{i z}\right)$ computed from grid $\mathrm{M}$ and the results computed by the other three grids, which can be calculated by use of Equation (7): 


$$
\left\{\begin{array}{l}
\theta_{i x}=\left(\theta_{i x}^{\mathrm{M}}+\theta_{i x}^{\mathrm{M}_{1}}+\theta_{i x}^{\mathrm{M}_{2}}+\theta_{i x}^{\mathrm{M}_{3}}\right) / 4 \\
\theta_{i y}=\left(\theta_{i y}^{\mathrm{M}}+\theta_{i y}^{\mathrm{M}_{1}}+\theta_{i y}^{\mathrm{M}_{2}}+\theta_{i y}^{\mathrm{M}_{3}}\right) / 4 \\
\theta_{i z}=\left(\theta_{i z}^{\mathrm{M}}+\theta_{i z}^{\mathrm{M}_{1}}+\theta_{i z}^{\mathrm{M}_{2}}+\theta_{i z}^{\mathrm{M}_{3}}\right) / 4
\end{array}\right.
$$

Figure 8 . The grids that the common node $i$ is in

The coordinates of rotation corners of each node of the standard template of the maximum deformation configuration in Figure 6 can be obtained in the same way. The initial solution needed by the one-step algorithm for bus rollover collision has theoretically no effect on the simulation results of the algorithm. However, the closer the configuration is to the true configuration, the higher the computational efficiency of the algorithm will be.

Order the coordinates of the rotation corners of node a in the maximum deformation configuration in Figure 7 is a $\left(\theta_{\mathrm{ax}}, \theta_{\mathrm{ay}}, \theta_{\mathrm{az}}\right)$, which can be calculated by use of Equation (8):

$$
\left\{\begin{array}{l}
\theta_{\mathrm{a} x}=\mathrm{N}_{1 \mathrm{~A}} \theta_{i x}+\mathrm{N}_{2 \mathrm{~A}} \theta_{j x}+\mathrm{N}_{3 \mathrm{~A}} \theta_{k x}+\mathrm{N}_{4 \mathrm{~A}} \theta_{l x} \\
\theta_{\mathrm{a} y}=\mathrm{N}_{1 \mathrm{~A}} \theta_{i y}+\mathrm{N}_{2 \mathrm{~A}} \theta_{j y}+\mathrm{N}_{3 \mathrm{~A}} \theta_{k y}+\mathrm{N}_{4 \mathrm{~A}} \theta_{l y} \\
\theta_{\mathrm{a} z}=\mathrm{N}_{1 \mathrm{~A}} \theta_{i z}+\mathrm{N}_{2 \mathrm{~A}} \theta_{j z}+\mathrm{N}_{3 \mathrm{~A}} \theta_{k z}+\mathrm{N}_{4 \mathrm{~A}} \theta_{l z}
\end{array}\right.
$$

where the values of $\mathrm{N}_{1 \mathrm{~A}}, \mathrm{~N}_{2 \mathrm{~A}}, \mathrm{~N}_{3 \mathrm{~A}}, \mathrm{~N}_{4 \mathrm{~A}}$ are the same with Equation (1), which are all known.

The coordinates of the rotation corners of each node of the maximum deformation configuration of rollover collision can be computed in the same way. By carrying out the computation process mentioned above, the maximum deformation configuration of rollover collision of the 12-meter bus needed by the one-step collision algorithm can be obtained by using a group of standard templates shown in Figure 3 and Figure 6. During the process of collision contact judgement and modification, the needed initial solution of the algorithm can be quickly obtained. Newton-Raphson iteration process is conducted for the generalized imbalanced forces of each node of the initial solution, and the final structure deformation is obtained.

\section{Case study}

A typical bus body section of a 12-meter bus is selected as the analytical object to verify the effectiveness of the improved one-step algorithm for bus rollover collision (Simplified as "The improved algorithm" below) by using the new initial solution prediction method proposed in this paper. The bus body section is properly simplified. By comparing the simulation result of the improved algorithm with the original algorithm, the practical application effect of the proposed improvement method is inspected. The typical bus body section model is shown as Figure 9.

Figure 9. The typical bus body section model

The critical angle of the bus body section rollover is $39^{\circ}$. Referring to the test model of typical bus body section, the model shown in Figure 10 is the FEA model, which is discretized with 259976 quadrilateral elements and 258368 nodes. The bus body section is fixed by a simple rollover bracket, and the minimum ground clearance is kept unanimous with the whole vehicle. The meterials of the 
structure skeleton and rollover rotation bracket both select Q345 steel. Elastic modulus is $\mathrm{E}=2.06 \times 10^{11} \mathrm{~Pa}$, Poisson coefficient is $\mu=0.3$, density is $\rho=7800 \mathrm{~kg} / \mathrm{m}^{3}$, and yield strength is $\sigma_{s}=345 \mathrm{MPa}$. The material of the passengers' living space is rigid, and the density value $\rho=10 \mathrm{~kg} / \mathrm{m}^{3}$ to avoid influencing the precision of the simulation result of the rollover collision algorithm [24]. For the bus rollover collision process is carried out at the state of low speed, the strain rate effects are not taken into consideration here.

Figure 10. The finite element model of the typical bus body section

Figure 11 shows the final deformation contour plot of the structure obtained by the improved algorithm. Figure 12 shows the deformation contour plot of the structure obtained by the original algorithm.

Figure 11. Deformation contour plot for the simulation of the improved algorithm

Figure 12. Deformation contour plot for the simulation of the original algorithm

Comparing Figure 11 and 12, the final deformation configurations of the improved algorithm and original algorithm give a reasonable agreement, which verified the feasibility of the practical engineering application of the proposed initial solution prediction method.

To make the comparing result above more convictive, the quantitative comparison for the final deformation of the two methods needs to be carried out. 11 gauging points are selected to collect the deformation data of the structure on each side of the pillars of the closed-loops (1) and (2) of the bus body section. The deformation amounts of each pillar of the two simulation methods mentioned above are shown in Table 1.

Table 1. Data of the deformations of both sides of each pillar

Figure 13 and 14 show the comparison line chart of the deformations of both sides of the pillars of two closed-loops (1) and (2).

Figure 13. Comparison of the deformations of gauging points of both sides of closed-loop (1)

Figure 14. Comparison of the deformations of gauging points of both sides of closed-loop (2)

By comparing the line charts above, it is found that the trends of the data of the two results are the same in general, which verifies the conclusion that the final deformation configurations give a reasonable agreement mentioned above. The computational precision of the improved algorithm and the original algorithm is about $0.4 \%$ difference. The precision can be regarded as the same, and 
the computational precision is basically kept.

Then, compare the computational efficiency of the improved algorithm and the original algorithm. The comparation result is shown as Table 2 .

Table 2. Data of the computation time

It can be obtained from the table that the computation time of the improved algorithm is about $30 \%$ of the original algorithm. Combining the comparing conclusion of the deformation amounts of the pillar, the computational precision of the improved algorithm is basically kept, while the computational efficiency gains a lot. In this way, the final deformation of rollover collision of the structure can be obtained faster and more accurately at the initial stage of bus structure design. The rollover safety performance of bus structure can be evaluated more quickly, and the development cycle for bus product can be reduced sharply one step further. Meanwhile, some necessary conditions can be supported for the further study of sensitivity analysis of bus rollover safety, parameter optimization, and the research of topology optimization algorithm.

\section{Summary and Conclusion}

To solve the problem that the computational efficiency of the initial solution prediction based on the maximum inertial loading in the original one-step algorithm for bus rollover collision is a bit low in some degree, a new initial solution prediction method based on the principle of nodal coordinates interpolation of the standard template of the structure deformation is proposed to carry out the improvement research on the original one-step algorithm for bus rollover collision. A case study on rollover collision for a typical 12-meter bus body section is carried out, and the simulation result of the improved algorithm is compared with the original algorithm. The computational precision of the improved algorithm is basically kept, and the computational efficiency is improved significantly at the same time. The practical effectiveness of the proposed improvement method is verified. The conclusion is obtained as follows:

- The final deformation configurations of the improved algorithm and original algorithm give a reasonable agreement, which verified the feasibility of the practical engineering application of the proposed initial solution prediction method.

- The computational precision of the improved algorithm and the original algorithm is about $0.4 \%$ difference. The precision can be regarded as the same, and the computational precision is basically kept.

- The computation time of the improved algorithm is about $30 \%$ of the original algorithm. The computational precision of the improved algorithm is basically kept, while the computational efficiency gains a lot.

However, the standard template obtained in this paper is suitable for the initial solution prediction of rollover collision of the 12-meter buses only, and is not suitable for the bus models of other lengths. The standard template of other models can be designed referring to the core idea of the proposed method in this paper, and the application scope of the initial solution prediction for the standard template method can be perfected further.

\section{Acknowledgments:}

This research was carried out under the NSFC project "Large-step, high-accuracy and fast sheet metal forming simulation approach based on quasi-deformation theory”, with project number 51075187.

This research was also carried out under the Shaanxi National Science Foundation project "Research of a high precision fast simulation optimization algorithm for bus rollover collision", 
with project number 2018JQ5213.

\section{Declarations:}

(1)Availability of data and materials

All data, models, and code generated or used during the study appear in the submitted article.

(2)Competing interests

The authors declare that they have no competing financial interests.

(3)Funding

This research was carried out under the NSFC project "Large-step, high-accuracy and fast sheet metal forming simulation approach based on quasi-deformation theory", with project number 51075187.

This research was also carried out under the Shaanxi National Science Foundation project

"Research of a high precision fast simulation optimization algorithm for bus rollover collision" , with project number 2018JQ5213.

(4)Authors' contributions

Author contributions: The author Tong Wang contributed to all the works for the whole article include the conception of the study, data analyzing, manuscript preparation and writing the manuscript.

\section{References:}

[1] L. G. Liu, J. X. Cheng. The relationship among automotive retention, GDP and related industry. Journal of Chang'an University (Social Science Edition), 7 (3) (2005), pp. 35-38.

[2] Y. Zhou, Z. B. Lei. Research on simulation of dynamic over turn test for bus. Automobile Science and Technology, 5 ( 2005), pp. 37-39.

[3] X. M. Zhou, F. C. Lan, J. Q. Chen, R. Xie. Research on analysis and optimization design of coach roll over based on FEM technology. Modern Manufacture Engineering, 5 (2010), pp. 115-118.

[4] Z. J. Fan, L. Ma, L. J. Gui, R. Y. Su. Multi-objective optimization for bus rollover safety. Journal of System Simulation, 24 (5) (2012), pp. 1109-1113.

[5] C. X. Ruan, L. B. Cao, X. N. Shi, Z. Xu. Lightweight design for bus body satisfied the rollover safety. Chinese Mechanical Engineering, 24 (7) (2013), pp. 975-979.

[6] J. X. Na, T. Wang, Z. W. Xu. Research on a one-step fast simulation algorithm for bus rollover collision based on total strain theory. International Journal of Crashworthiness, 19 (3) (2014), pp. 275-287.

[7] J. L. Batoz, Y. Q. Guo, P. Duroux, J. M. Detraux. An efficient algorithm to estimate the large strains in deep drawing. NUMIFORM'89, Fort Collins, CO, USA, A. A. Balkema, Rotterdam, 383 (1989).

[8] Y. Q. Guo, J. L. Batoz, J. M. Detraux, P. Duroux. Finite element procedures for strain estimations of sheet metal forming parts. International Journal for Numerical Method Engineering, 39 (1990), pp. 1385-1401.

[9] Y. Q. Guo, J. L. Batoz, M. M. El, J. M. Detraux. On the estimation of thickness strains in thin car panels by the inverse approach. NUMIFORM'92, (1992), pp. 1403-1408.

[10] J. L. Batoz, Y. Q. Guo, F. Mercier. The inverse approach with simple triangular shell elements for large strain predictions of sheet metal forming parts. Engineering Computations, 15 (7) (1998), pp. 864-892.

[11] Y. Q. Guo, J. L. Batoz, H. Naceur, S. Bouabdllah. Recent developments on the analysis and optimum design of sheet metal forming parts using the simplified inverse approach. Computers and Structures, 78 (2000), pp. 133-148. 
[12] Y. Q. Guo, H. Naceur, K. Debray, F. Bogard. Initial solution estimation to speed up inverse approach in stamping modeling. Engineering Computations, 20 (7) (2003), pp. 810-834.

[13] Q. Y. Shen, Y. P. Wei, G. Y. Wang, X. Y. Ruan. The finite element analysis of sheet metal forming based on the deformation theory. Mould Technology, 5 (1999), pp. 3-6.

[14] Q. Y. Shen, Y. P. Wei, G. Y. Wang, X. Y. Ruan. One step finite element simulation of sheet metal forming. Journal of Shanghai Jiao Tong University, 34 (10) (2000), pp. 1404-1405.

[15] Q. Y. Shen, Y. P. Wei, G. Y. Wang, C. L. Zhao, X. Y. Ruan. Fast finite element analysis for sheet metal forming. Journal of Computational Mechanics, 17 (2) (2000), pp. 242-245.

[16] Y. Q. Liu, P. Hu, Y. Cao, Y. X. Li. Numerical method for simulation of forming process of automobile panel forming process. Automobile Engineering, 19 (2) (1997), pp. 25-29.

[17] Y. Q. Liu, P. Hu, W. Guo, Y. X. Li. Numerical simulation of local plastic instability and wrinkling in sheet forming. Journal of Mechanical Engineering, 33 (2) (1997), pp. 88-92.

[18] J. W. Wang, P. Hu, Z. C. Fu, Y. W. Xu. Experiment on the springback of auto body panel parts and CAE analytical method based on universal formability technology. Journal of Plastic Engineering, 17 (1) (2010), pp. 41-45.

[19] J. X. Na, H. Gao, L. Zhang, P. Hu. Selection algorithm of relaxation factor in one step forming simulation approach. Journal of Jilin University (Engineering and Technology Edition), 35 (3) (2005), pp. 292-296.

[20] J. X. Na, W. Chen. One step positive approach for sheet metal forming simulation based on quasi-conjugate-gradient method. Chinese Journal of Mechanical Engineering, 26 (4) (2013), pp. 731-737.

[21] J. X. Na, W. Chen, H. P. Liu. One-step inverse approach based on quasi-conjugate-gradient method. Journal of Advanced Manufacturing Systems, 11 (2) (2012), pp.165-172.

[22] W. Chen, J. X. Na. One step forming positive algorithm based on the total strain theory. Journal of Jilin University (Engineering and Technology Edition), 43 (2) (2013), pp. 358-362.

[23] Y. Liu, C. Yao, J. X. Na. Structural design of variable cross-section stamping column to improve bus rollover safety. Journal of Jilin University (Engineering and Technology Edition), 44 (1) (2014), pp. 17-21.

[24] C. Luis, C. Jesus, M. Antonio, et al. Simulation and testing of composite buses rollover. SAE Paper, 2004-1-0741. 


\section{List of figures}

Figure 1. The finite element model of three closed-loop structures

Figure 2. The standard template of the original configuration of three closed-loop structures

Figure 3. The standard template of the original configuration

Figure 4. The final deformation of rollover collision of the three closed-loop structures

Figure 5. The standard template of maximum deformation configuration of the three closed-loops

Figure 6. The standard template of maximum deformation configuration

Figure 7. The nodal corresponding relations of the group of standard templates

Figure 8. The grids that the common node $i$ is in

Figure 9. The typical bus body section model

Figure 10. The finite element model of the typical bus body section

Figure 11. Deformation contour plot for the simulation of the improved algorithm

Figure 12. Deformation contour plot for the simulation of the original algorithm

Figure 13. Comparison of the deformations of gauging points of both sides of closed-loop (1)

Figure 14. Comparison of the deformations of gauging points of both sides of closed-loop (2) 
Figure1
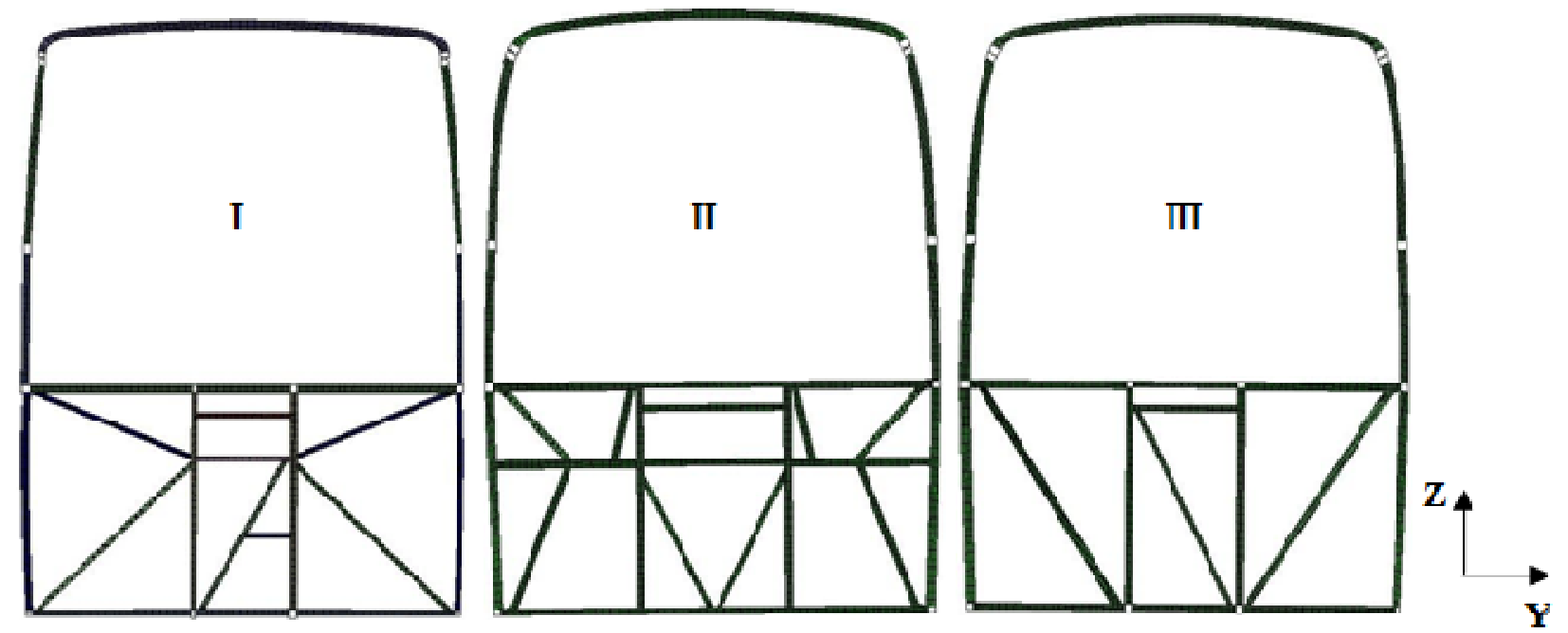

Figure2
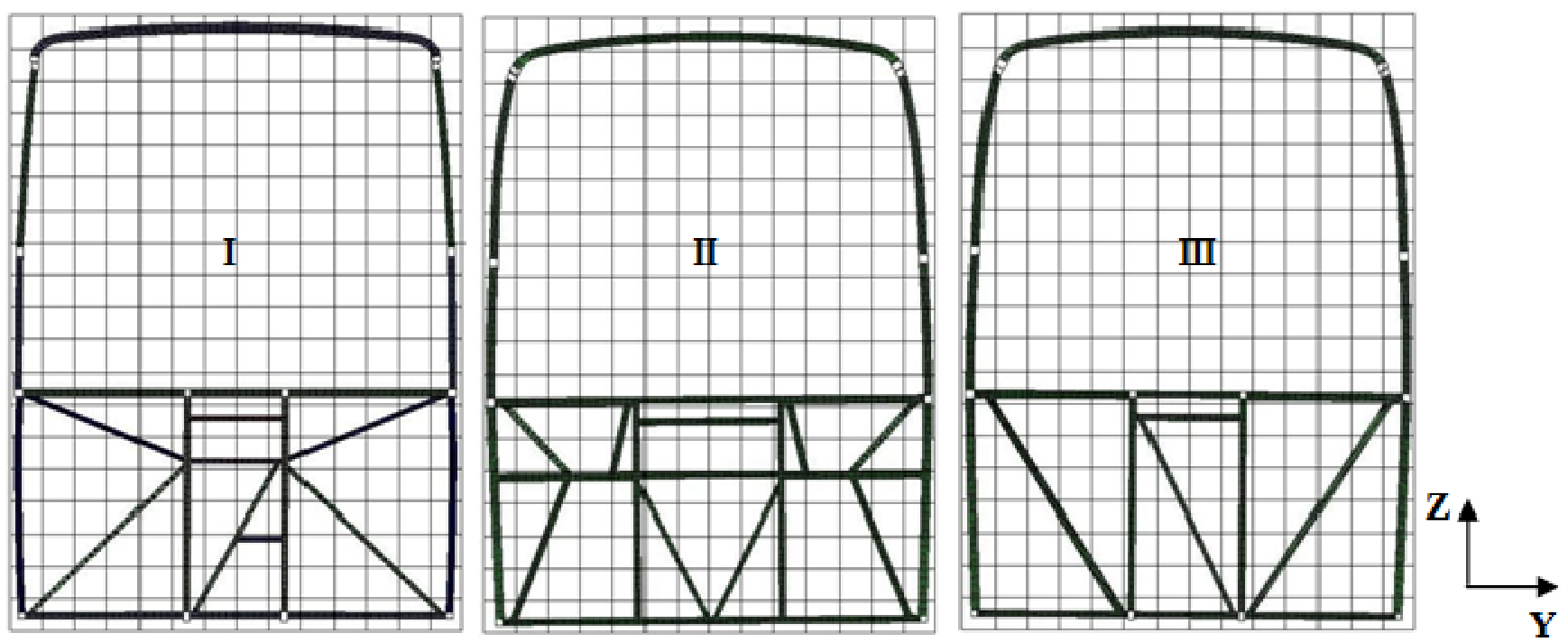

Figure3

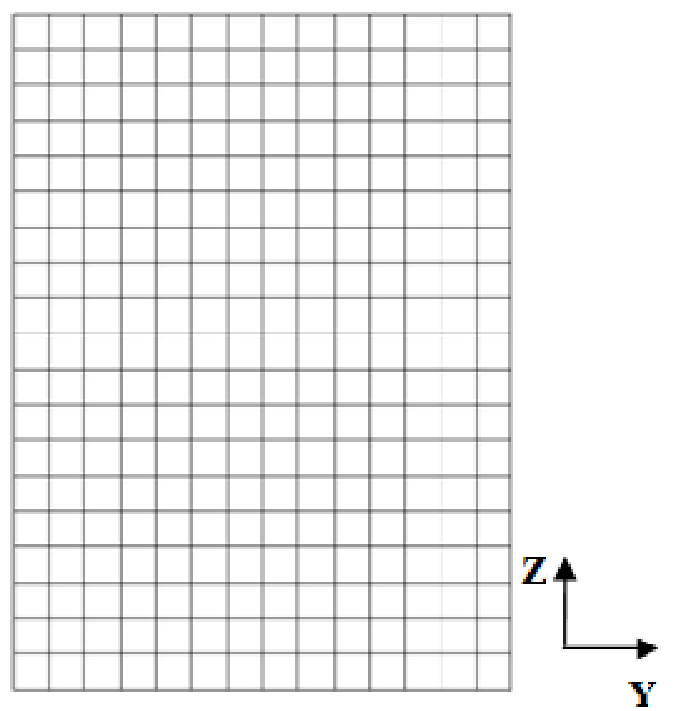


Figure4

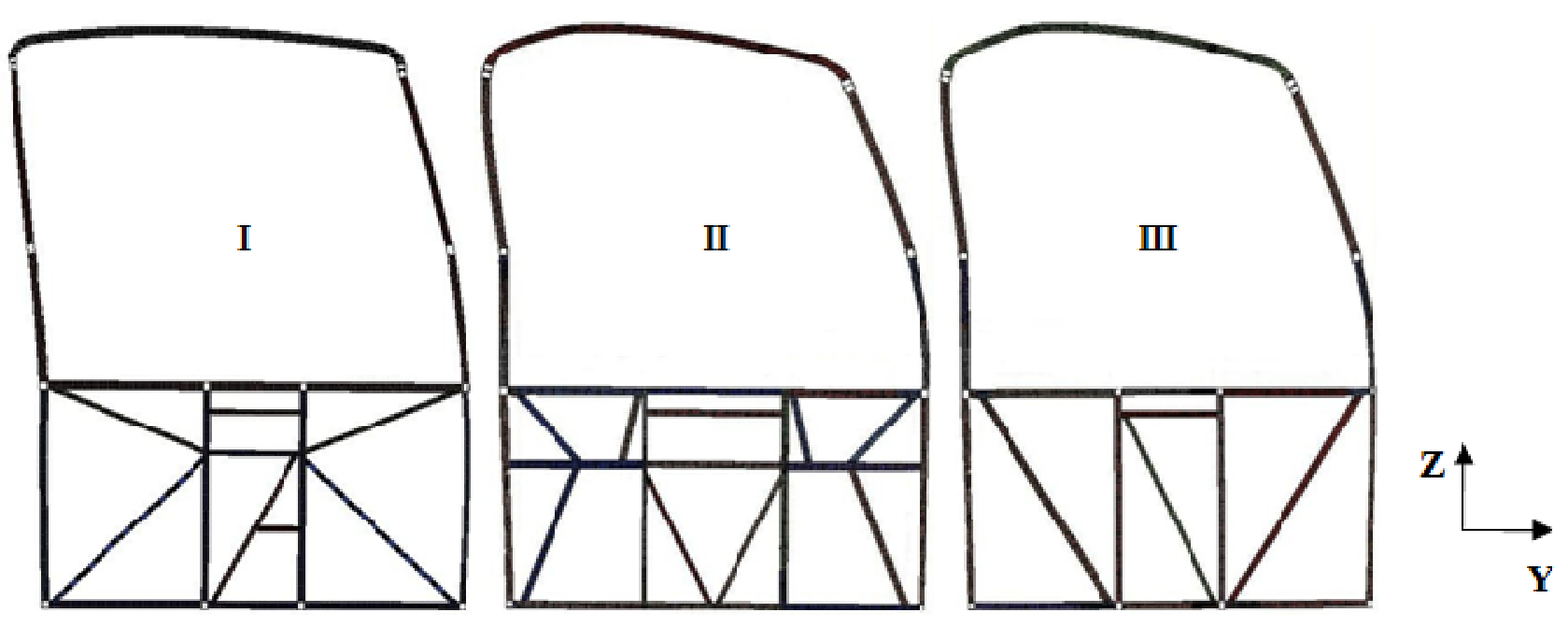

Figure5
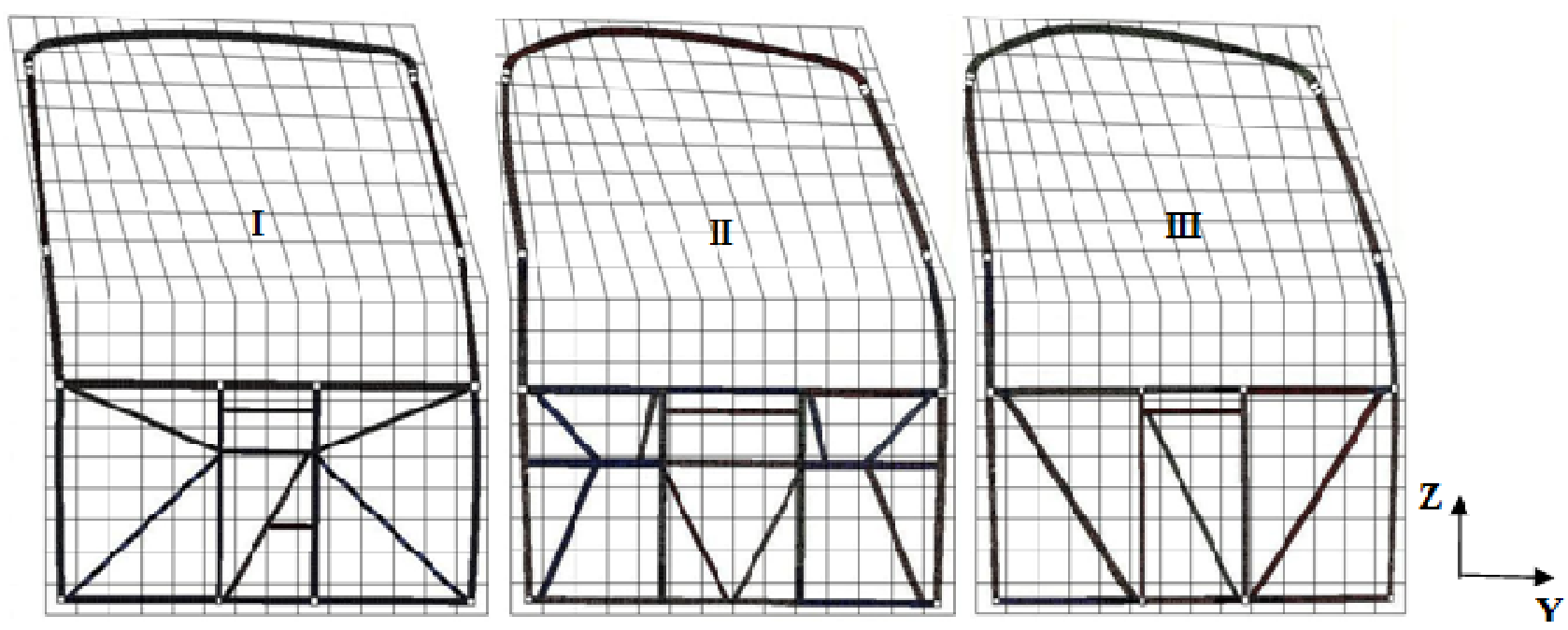

Figure6
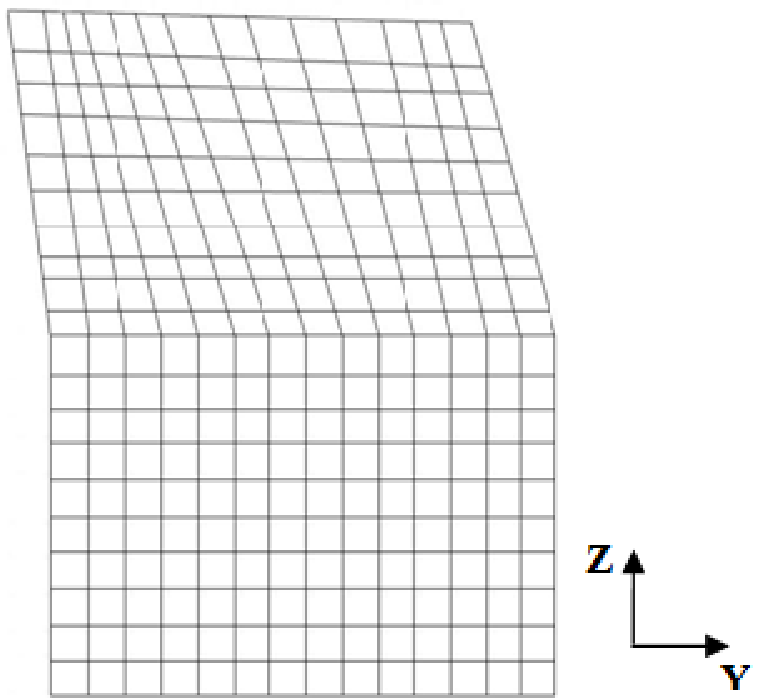
Figure7
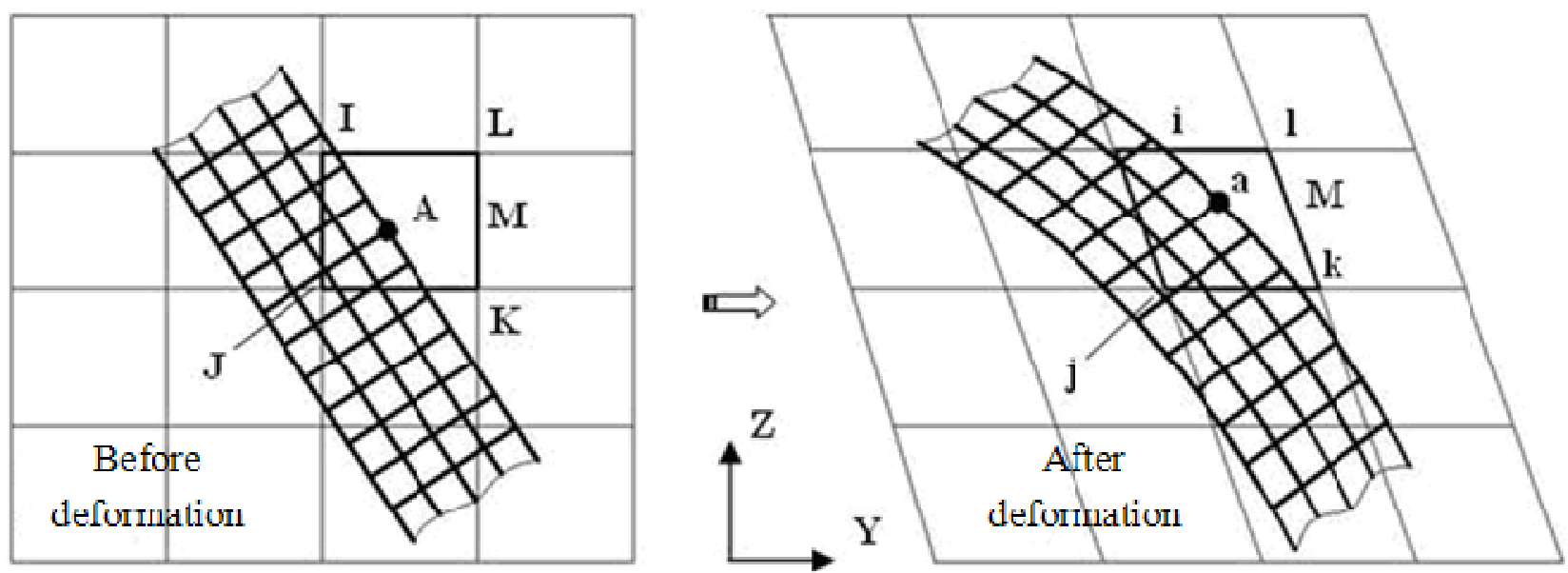

Figure8

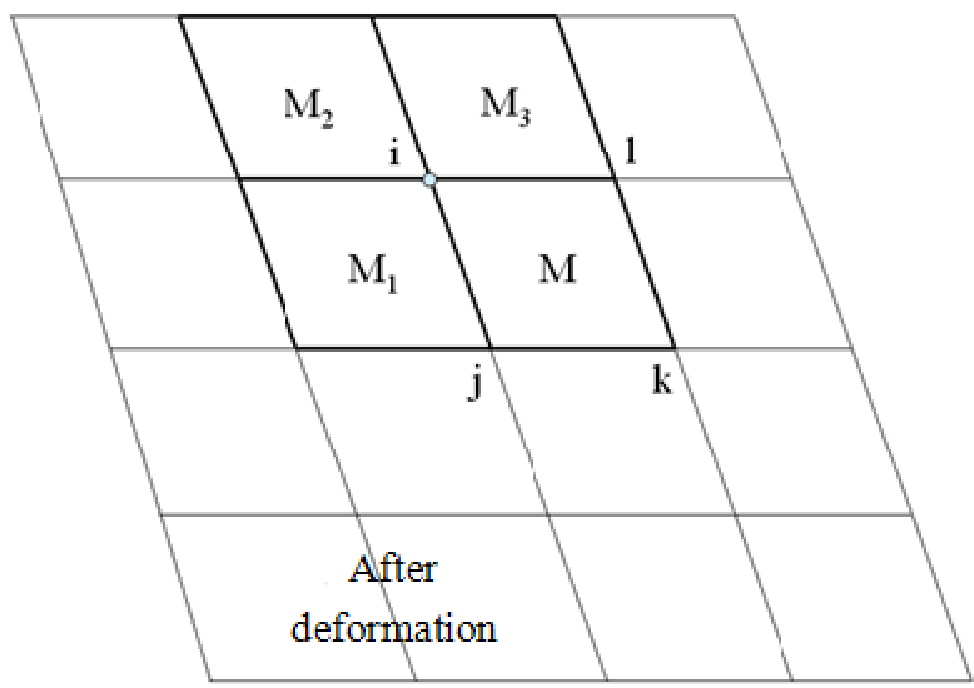

Figure9

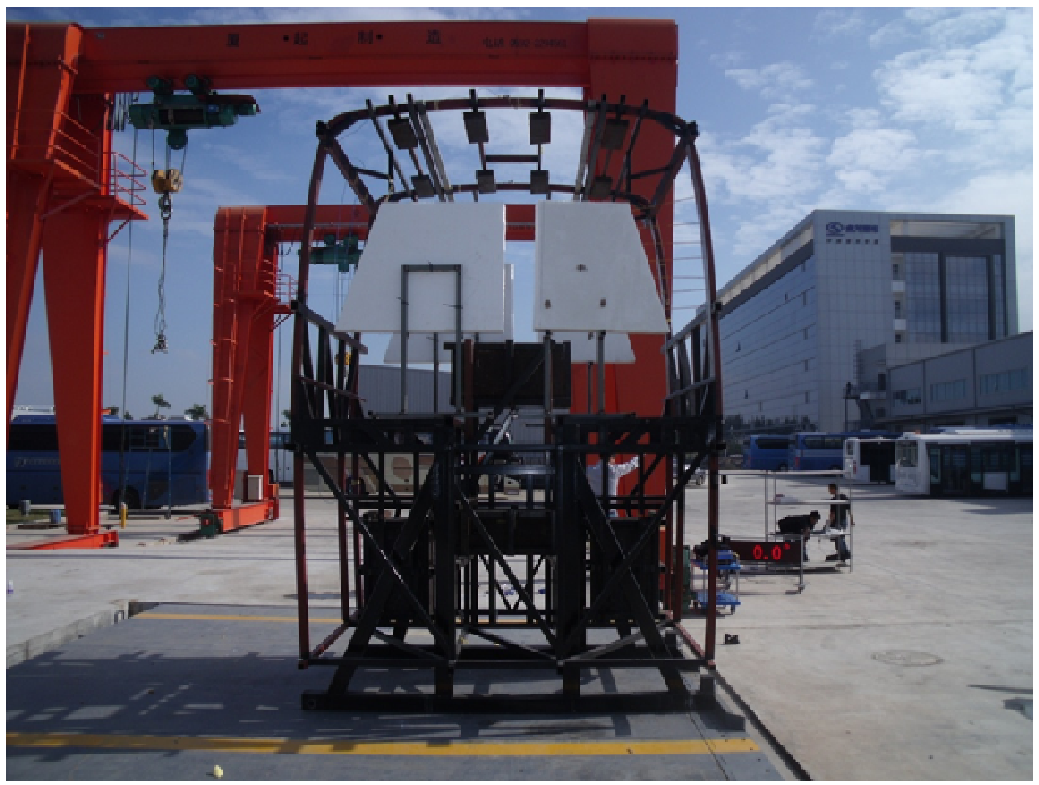


Figure10

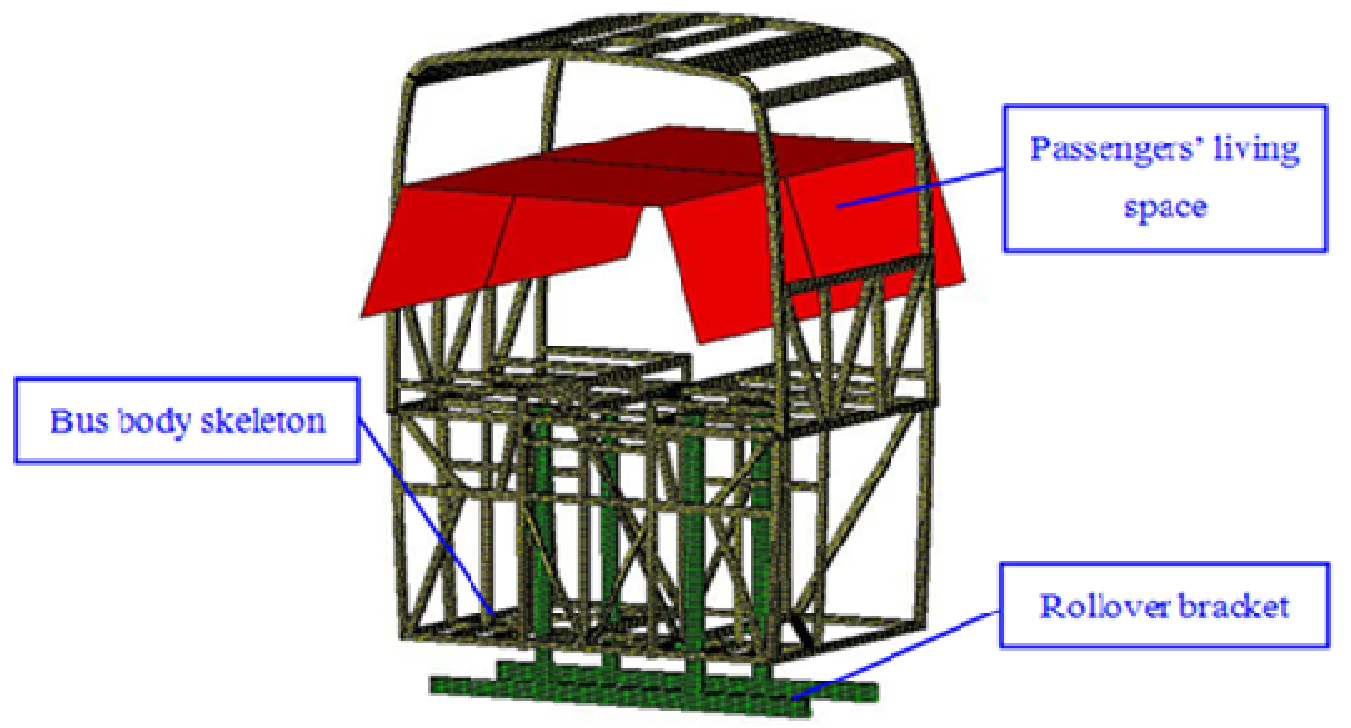

Figure11

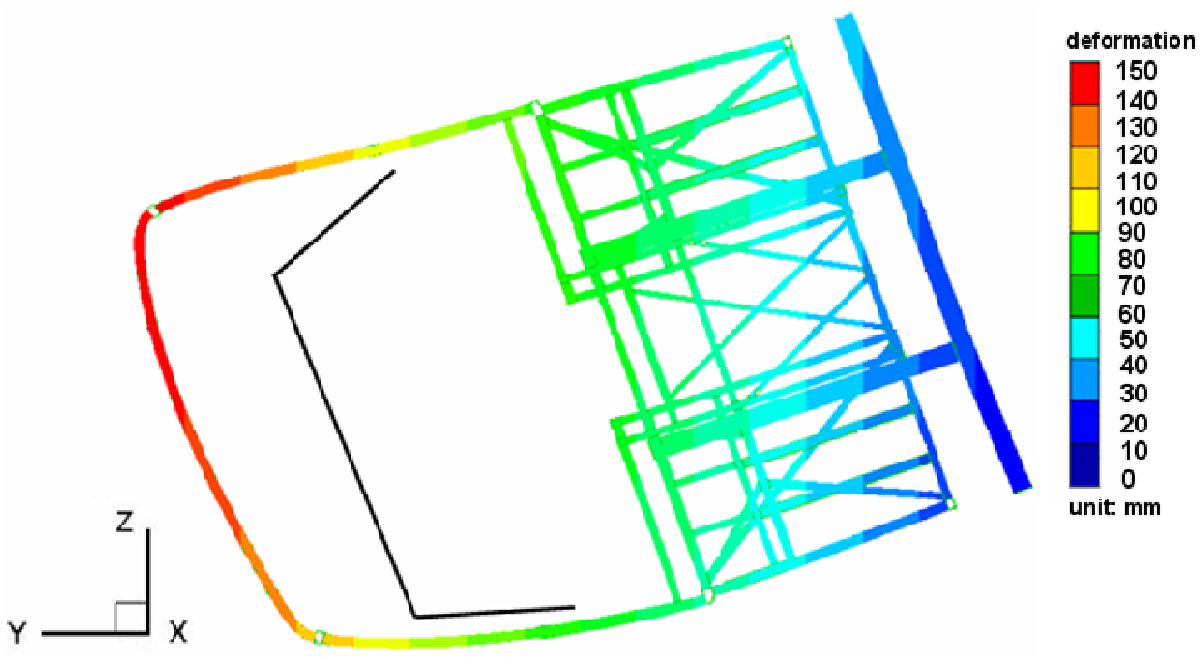

Figure12

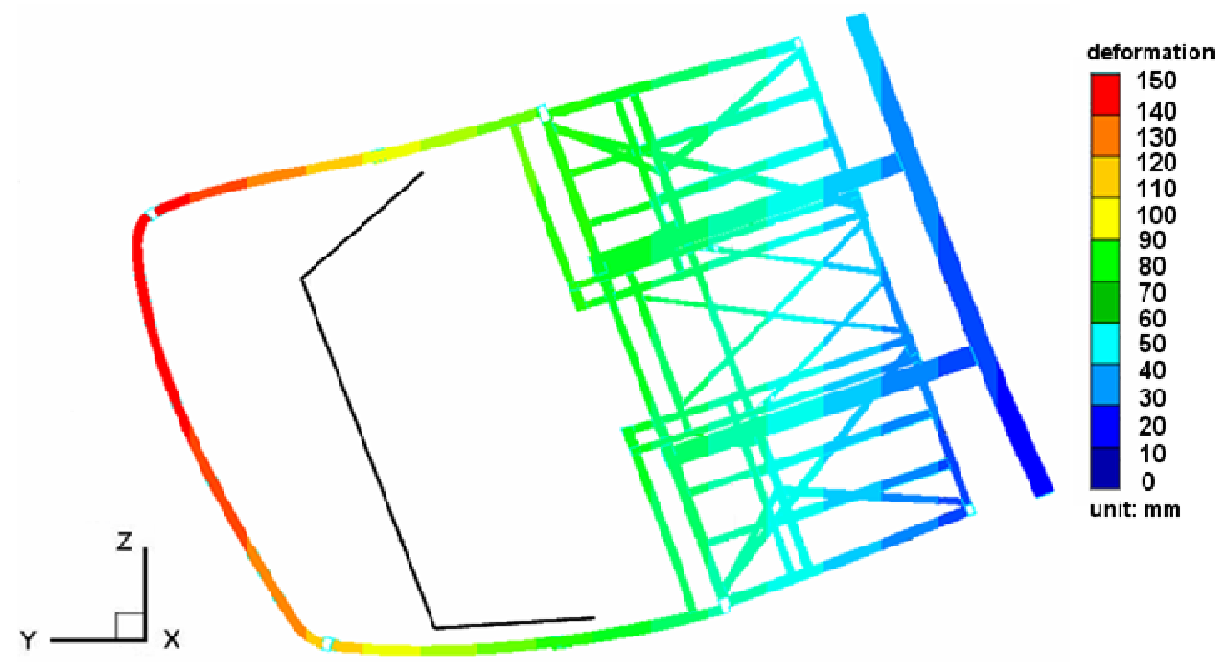


Figure13

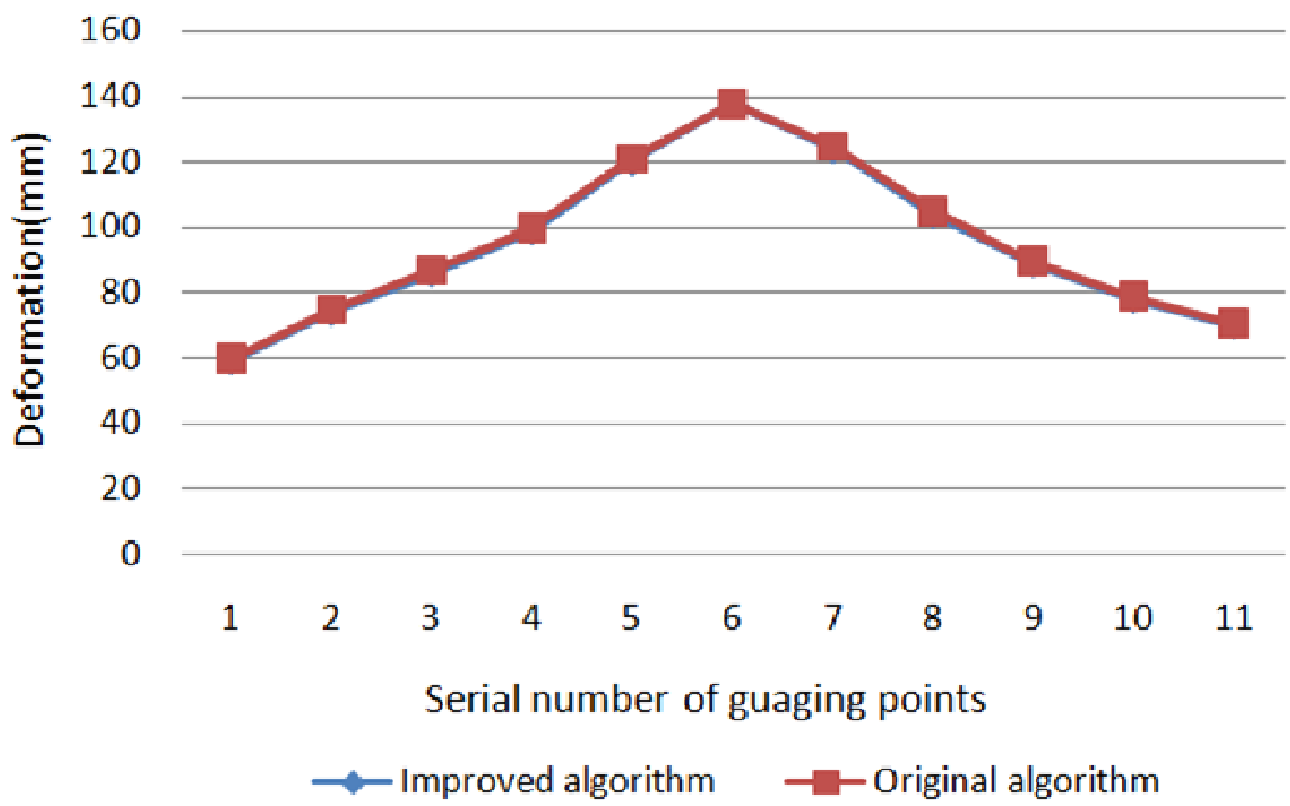

Figure14

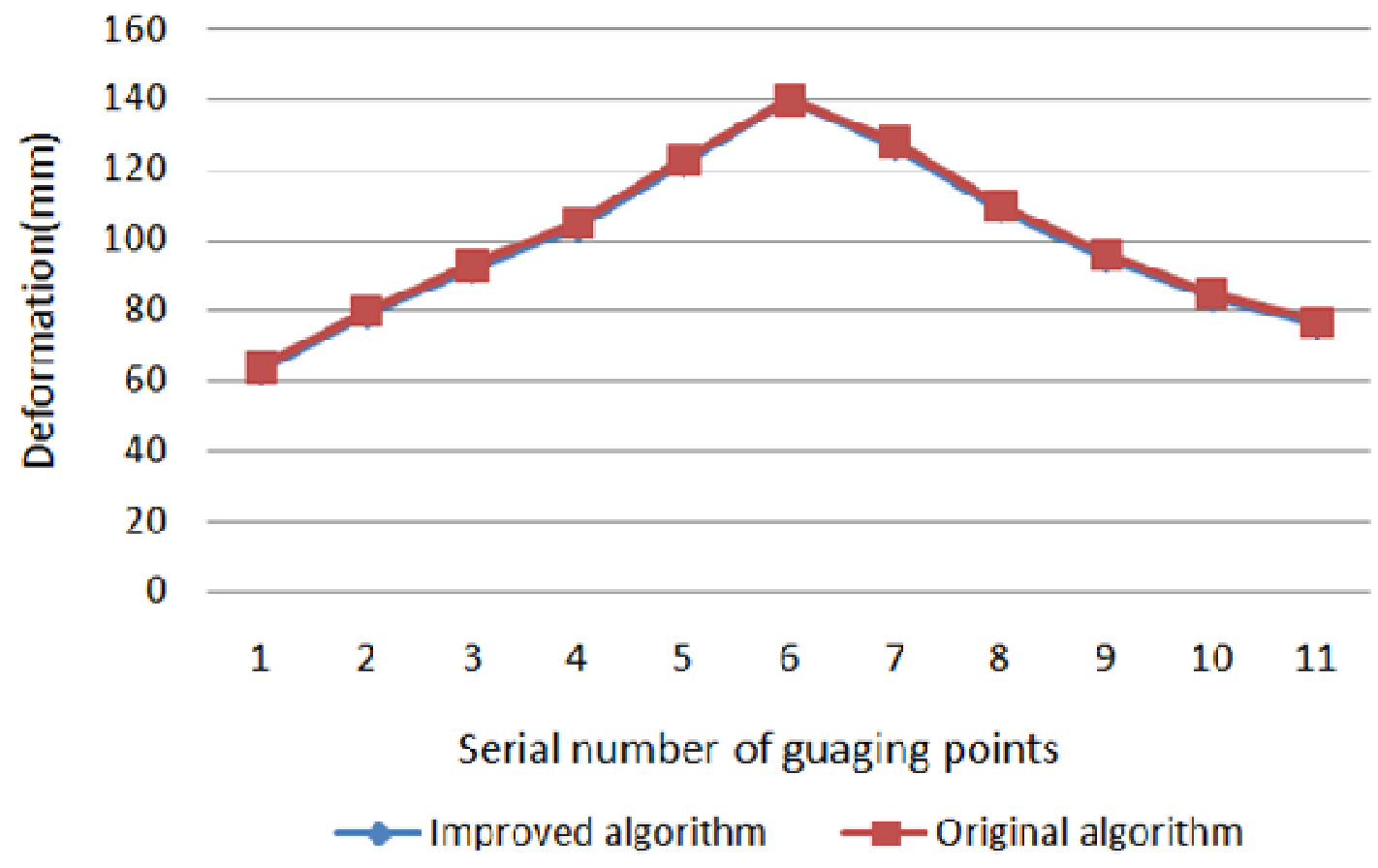




\section{List of tables}

Table 1. Data of the deformations of both sides of each pillar

Table 2. Data of the computation time

Table 1. Data of the deformations of both sides of each pillar

\begin{tabular}{ccccc}
\hline \multirow{2}{*}{$\begin{array}{c}\text { Serial number of } \\
\text { gauging points }\end{array}$} & \multicolumn{2}{c}{ Improved algorithm (mm) } & \multicolumn{2}{c}{ Original algorithm (mm) } \\
\cline { 2 - 5 } & Closed-loop (1) & Closed-loop (2) & Closed-loop (1) & Closed-loop (2) \\
\hline 1 & 59 & 63 & 60 & 64 \\
2 & 74 & 79 & 75 & 80 \\
3 & 86 & 92 & 87 & 93 \\
4 & 99 & 104 & 100 & 105 \\
5 & 120 & 122 & 121 & 123 \\
6 & 138 & 140 & 138 & 140 \\
7 & 124 & 127 & 125 & 128 \\
8 & 104 & 109 & 105 & 110 \\
9 & 89 & 95 & 90 & 96 \\
10 & 78 & 84 & 79 & 85 \\
11 & 70 & 76 & 71 & 77 \\
\hline
\end{tabular}

Table 2. Data of the computation time

Simulation time Improved algorithm Original algorithm

\begin{tabular}{ccc}
\hline $\mathrm{T}(\min )$ & 6 & 20 \\
\hline
\end{tabular}

